\title{
Empowering the lowland indigenous community through child health and nutrition program in Occidental Mindoro Province, Philippines
}

Artemio Morado Gonzales Jr

Occidental Mindoro State College, Philippines, jomergonzalesjr21@gmail.com

Follow this and additional works at: https://scholarhub.ui.ac.id/ajce

Part of the Community Health and Preventive Medicine Commons, Maternal and Child Health Commons, Nursing Midwifery Commons, Pediatric Nursing Commons, Public Health and Community Nursing Commons, and the Public Health Education and Promotion Commons

\section{Recommended Citation}

Gonzales, Artemio Morado Jr (2020). Empowering the lowland indigenous community through child health and nutrition program in Occidental Mindoro Province, Philippines. ASEAN Journal of Community Engagement, 4(1).

Available at: https://doi.org/10.7454/ajce.v4i1.1081

Creative Commons License

\section{(c) (i) ()}

This work is licensed under a Creative Commons Attribution-Share Alike 4.0 License.

This Research Article is brought to you for free and open access by the Universitas Indonesia at ASEAN Journal of Community Engagement. It has been accepted for inclusion in ASEAN Journal of Community Engagement. 


\title{
Empowering the lowland indigenous community through child health and nutrition programs in Occidental Mindoro Province, Philippines
}

\author{
Artemio Morado Gonzales Jr ${ }^{\mathrm{a}^{*}}$ \\ a Occidental Mindoro State College, Philippines
}

Received: April 2nd 2020 || Revised: April 20"th 2020 || Accepted: July 29 ${ }^{\text {th }}, 2020$

\begin{abstract}
Nutrition and child health programs were integrated into the extension programs from 2016-2018 of the Occidental Mindoro State College, in partnership with the local government unit at the municipal and barangay levels. This paper presents the health extension tools and techniques used in preventative care and the promotion of child health services in the indigenous community of Sitio Bato Singit, in the Occidental Mindoro Province, Philippines. Health education, small group techniques, demonstrations, storytelling, informal talks, and open forums were the methods and techniques employed to implement the program. The common tools used were seating arrangements, flip-charting, props, social hours, and recreation. In terms of the evaluation of the program, child health outcomes remain poor, despite the efforts of the different blocks working within the health system. These programs could enhance their health knowledge and practices in other extension modalities.
\end{abstract}

Keywords: child health; nutrition; health extension; empowerment; community organizing.

\section{Introduction}

Due to the scarcity of the health workers worldwide, community health workers are widely used to provide care for a broad range of health issues especially in the developing countries as they are the first responders of universal health coverage (Desta \& Basha, 2017; Tangcharoensathien et al., 2018). However, there is limited evidences from available sources about the effectiveness of establishing community health workers in implementing comprehensive primary health care, especially as regards child health, the primary indicator of a country's health status (Vasan et al., 2017).

In the Philippines, despite of the the efforts in reducing both infant and under-fiveyear-old child mortality rates, the performance in reducing maternal and fetal death rates is not as commendable. Nowadays, infectious diseases and accidents remains the cause of child and infant deaths. Lastly malnutrition in children under five has also shown very slow progress in the country (Cetrángolo, Mesa-Lago, Lazaro, \& Carisma, 2013).

\footnotetext{
*Correspondence Author: jomergonzalesjr21@gmail.com
} 
"Am boyag, ko boyag" is a Buhid translation for "my life, your life." It is contextualized in the philosophy that the life processes of other people in the community are the shared responsibility of every member. The health of an individual is a reflection of public efforts toward a healthcare for the common good. Children's health is vital to the nation's present and future and reflects the way's communities address their collective commitment to children. Different efforts concerning future generations are at the center of the United Nations Sustainable Development Goals (SDGs) endeavor. The current study further theorizes on the concept of sustainability around children's health and wellbeing. The health of children and their future is intimately linked to the health of our planet (Clark et al., 2020).

Based on the United Nations Declaration on the Rights of Indigenous Peoples, "indigenous peoples have the right to their traditional medicines and to maintain their health practices, including the conservation of their vital medicinal plants, animals and minerals. Indigenous individuals also have the right to access, without any discrimination, to all social and health services. In addition, indigenous individuals have an equal right to the enjoyment of the highest attainable standard of physical and mental health. States shall take the necessary steps with a view to achieving progressively the full realization of this right" (United Nations, 2007). With this challenge, health care workers must integrate social perspective in the promotion of healthcare access. This suggest that health extension workers are well situated to influence these social aspects, improving access to healthcare services broadly, and among indigenous people (Horrill, McMillan, Schultz, \& Thompson, 2018).

In many ways, children's health depends on how well a country tends to its environment (Ribeiro et al., 2016). Changing patterns of childhood illness, including infectious diseases, are often based on poor environmental sanitation (Prüss-Ustün et al., 2017). The promotion of a healthy environment can significantly reduce the incidence of premature deaths and, by extension, minimize the significant healthcare costs of environment-related diseases (Shrivastava, Shrivastava, \& Ramasami, 2016). Sanitation and hygiene are key to children's survival, development, and growth (Russell \& Azzopardi, 2019). Holistic solutions are required that consider economic feasibility and all the various aspects of sanitation, including government support, social acceptability, as well as technological applications that can be effectively adapted to local conditions (Zhou et al., 2018). A study from Nigeria suggests promotion of informal training and 
Artemio Morado Gonzales Jr | ASEAN Journal of Community Engagement | Volume 4, Number 1, 2020

education to women without formal education increase their knowledge, and practices in health and nutrition which in turn enhance child nutrition outcomes (Fadare et al., 2019).

Several priority interventions have been offered to improve childhood nutrition in developing countries. These include a wide range of expertise, methods, and data. Priorities in child health and nutrition suggests the combination of interventions to improve diet quality and other supplemental food to the at-risk mothers and children (Masters et al., 2018). Elsewhere, the strong design and integration of water, sanitation, and hygiene (WASH), and nutrition interventions are evidently progressing. To identifying factors that enable or interfere with progressive outcomes several context are suggested to determine. Inclusion of theory-based and evidence-based behaviorchanging strategies are also being applied (Aboud \& Yousafzai, 2018). The integration of different programs in child health and nutrition is likely to foster additional benefits for young children without undermining the original service. However, the results of the implementation only show the positive effects on the child's development and less on their nutritional status. Thus, it's important to improve the functioning of the programs and to establish quality control mechanisms (Grantham-Mcgregor, Fernald, Kagawa, \& Walker, 2014).

A study suggests timely modifications to more effectively integrate the child development schemes and consider strategies to bring desired improvements in children's health. This strategy includes specific nutritional interventions such as infant and young childcare and nutrition, maternal care nutrition and health, and adolescent care, while addressing other health services. All districts having high rates of malnutrition should also be targeted, with the nutritional status consistently measured in real time. Newer interventions include height measurements of children, social audits, and establishing nutrition resource centers, to promote community involvement in nutrition efforts (Aggarwal \& Kakkar, 2019).

\subsection{Community development through conscientization and behavior change}

The concept of conscientization is defined by the Brazilian educator Paolo Friere in his Pedagogy of the Oppressed as "learning to perceive social, political, and economic contradictions, and to take actions against the oppressive elements of reality" (Freire, 1998). The idea concerns education for critical consciousness. Friere came to believe that 
a necessary condition for social symmetry in education and in society in general was to concentrate on a community's practical problems, (Stańczyk \& Gdański, 2017). "Emancipatory transformation is not an event or classroom project but a sustainable way of being supported by a community of people who are motivated and committed by their own need for conscientization enlightenment" (Dawson \& Avoseh, 2018). A study revealed that application of holistic framework that is based theories and solutions-based approaches governs the idea of sustainability. It also revealed that critical times and conditions require critical measures and interventions, it is believed that novel sustainability imaginations and applications will emerge from this process of holistic conscientization (Ferreira, 2017). This concept has been adopted by several implementers in response to sanitation and nutrition services (Agbezuge, 2018; Sesan, Jewitt, Clifford, \& Ray, 2018).

The theory of planned behavior is a "prominent framework for predicting and explaining behavior in a variety of domains. The theory is also increasingly being used as a framework for conducting behavior change interventions. It is shown that the interventions' effectiveness varied for the diverse behavior change methods. In addition, interventions conducted in public and with groups were more successful than interventions in private locations or focusing on individuals which is moderated by gender and education" (Steinmetz et al., 2016). A study revealed that behavior change theory is an effective tool in improving hygiene and sanitation related issues; however, these theories have not been extensively examined (Srigley et al., 2015). Rigorous implementation of large scale interventions deployed in the context of a developing community have focused on high technology using different behavioral change strategies in improving water, sanitation and hygiene practices (Parvez et al., 2018) which can be limited in the underdeveloped and developing countries. Several projects in WASH and nutrition utilize behavioral change (Belizario et al., 2015; De Buck et al., 2018; Mbuya et al., 2015), suggesting that developers work with stakeholders to create a relevant theory.

\subsection{Promoting self-empowerment in the community}

Community empowerment refers to the process of enabling communities to increase control over their lives. Engagement is very important to the concept of empowerment. The community is invited to develop their potential together. People who want to learn 
Artemio Morado Gonzales Jr | ASEAN Journal of Community Engagement | Volume 4, Number 1, 2020

want to be empowered. Community learning can improve mental models, systems thinking, determining and implementing the vision of self, and organization in society, as well as the willingness to develop themselves and their personalities (Yuesti \& Sumantra, 2017). Communities have different cultures, norms and beliefs related to shared and individual practices which may later affect the competence, engagement, and capacity of the community. These differences may also affect the overall perception of health and later impede the health system efforts to promote health (Ferguson, Swan, \& Im, 2019).

Even if the program has a potential impact, community members could only benefit from it if they know about it and are willing to make use of its services. The acceptance of the program by community members is an important driver of program success. Apart from the individual engagement in pursuing the activities, and the magnitude of program promotion in the neighborhoods, networks of peers and kin play a particularly important role (Hoffmann, 2017). A study shows that creating psychologically-informed interventions to increase engagement in health-promoting behaviors leads to better health outcomes among low-income adults, particularly in racial/ethnic minorities (Tucker et al., 2018). It was also proven that good community-level health care and holistic development can result in good national health outcomes, and that ideal community health and development can only be attained by participation and empowerment. Hence, the metrics for community empowerment should be developed and implemented by government toward sustainable health and development, while ensuring the scientific validity of community health interventions (Co et al., 2018).

The purpose of this community engagement is to offer preventive and promotive child health services in the indigenous community of Sitio Bato Singit. Through the integration of different health programs and the application of conscientization and behavior changes, the programs become a good example for Occidental Mindoro as well as in the Philippines at large. This paper also presents the strategies and methods utilized to implement the program, as well as the constraints and lessons. 


\section{Methods}

\subsection{Study design}

Using the Community Organizing Participatory Action Research (COPAR) approach, the extension program utilized multimethod data gathering technique to design the program (Figure 1).

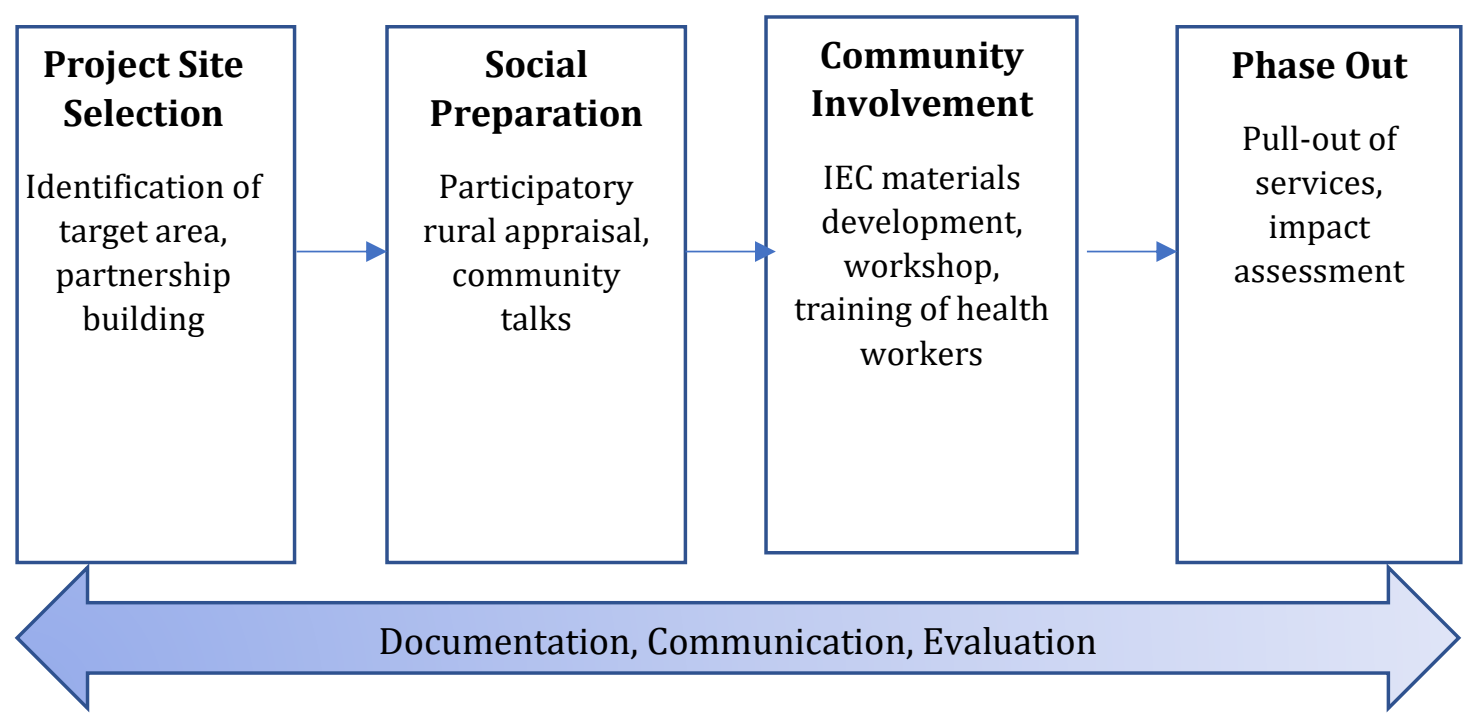

Fg. 1 COPAR Approach to Implementing Community Engagement

\subsubsection{Study site}

Sitio Bato Singit is in Barangay Manoot in the munipality of Rizal and province of Occidental Mindoro. The Buhid Mangyans are one of the few indigenous groups in the Philippines who continue to use their original syllabary. The ancestral land plays a significant role in the life of the Buhid Mangyans. Other than a source of subsistence, the land represents the identity, culture, spirituality, and legacy of the Buhid Mangyans. Accordingly, the ancestral land itself and its natural environment are well-maintained. The Buhid Mangyan are known to be farmers. Swidden farming or kaingin has always been their main source of livelihood. This process entails slash-and-burn forest vegetation to concentrate soil nutrients into a carpet of ash and ensure that the forestcover will be quickly replaced with cultivated plants and trees.

The Buhid Mangyan used to have an indigenous political structure headed by a Gurangon, also known as Tanungan. The Gurangon/ Tanungan are leaders for each big river (Safa Dahol). The river defines a cluster composed of a number of associated communities where each community is headed by a leader called Tahinan. Presently, only 
Artemio Morado Gonzales Jr | ASEAN Journal of Community Engagement | Volume 4, Number 1, 2020

the tahinan exists in the form of sitio leaders. To this end, leadership is based on election. These leaders are responsible for the management of their ancestral domain (NewCAPP, 2014).

\subsubsection{Partnership}

The institutional implementer of the extension project is Occidental Mindoro State College. Through its Research, Development, and Extension Unit, the College forged an agreement with the local government unit of Rizal, Occidental Mindoro Province, about the various programs offered by the institution, and dubbed it "GREEN WEALTH" Governance, Renewable Energy, Education, Nurturance, Women, Environment Agriculture, Livelihood, and Health - a unified extension program wherein all the colleges and departments contributed. The programs on women, nurturance, and health were established under the banner of its adopted community in Barangay Manoot, where Sitio Bato Singit of the Buhid Tribe is situated. It is with the proper guidance of the GREEN WEALTH Program, a strategic extension agenda, as well as the unified extension program of the college, which was the result of the internal and external analysis made and the consultation with stakeholders.

In coordination with the Barangay Council of Manoot in the Municipality of Rizal, the Municipal Health Offices and Local Government Unit (LGU) of Rizal in the province of Occidental Mindoro, the extension implementers forged a partnership and introduced accessible health promotion interventions in the community with the National Red CrossOccidental Mindoro Chapter, through the Red Cross Youth Club, as part of the student organization community engagement.

Moreover, preventive and promotive health measures were conducted the request of community leaders. The extension implementers collaboratively engaged different groups and government agencies in the province to participate in delivering community health services.

\subsubsection{Participatory rural appraisal}

Benchmarking is a significant instrument through the Participatory Rural Appraisal to appraise the health needs of the community prior to initiating the extension activities. A Community Health Survey was conducted to assess family and community health 
conditions as a form of Rapid Rural Appraisal. Extension workers also employed a Participatory Rural Appraisal (PRA) to consider the main health needs of mothers and children and possible solutions. After the PRA and the validation of data, the program implementer devised plans and programs in collaboration with barangay health workers (BHWs), rural health midwives (RHM), municipal health officers (MHO), barangay officials, and elders and tribal leaders. This formed the basis of the extension activities.

Students were also involved in the data collection, such as conducting the survey, key informant interviews, and focus group discussions as part of their training in public and community health. Those were Primary Health Care (the focus of community organizing and participatory action research, or COPAR) and Community Health Services Management. Students were the most dependable for those activities since faculty members do not participate in the extension program. They believe that the PRA, Training Needs Assessment, preparing the training design, coordinating with the community, and conducting the extension, monitoring, and evaluation already make for a tasking job (Declaro-Ruedas \& Lumbo, 2017).

After validation of community health surveys and health needs assessments, the next step was to devise plans and programs with the Barangay Health Council, the RHM, and the MHO. These formed the basis of extension activities.

\subsubsection{Impact assessment for phase out}

In order to prepare the necessary data for the Phase Out and the sustainability development, the implementer conducted a nutrition and child-feeding survey. At this point, the extension implementer conducted an impact assessment before pulling out of the extension services in the community.

The impact assessment involved an anthropometric survey of 6-59-month-old toddlers. The instrument also included introduction and consent statements, questions on selected household characteristics, like access to health and nutrition programs and consultation services, vitamin A supplements, deworming, and childhood vaccinations. Anthropometric measurements were also gathered: height, weight, and mid-upper arm circumference (MUAC) and bilateral edema.

MUAC measurements were taken from the toddlers using MUAC tapes for children. MUAC was measured on their left arms. In getting the MUAC, the midpoint of the left arm 
Artemio Morado Gonzales Jr | ASEAN Journal of Community Engagement | Volume 4, Number 1, 2020

was identified by bending it 90 degrees and then locating the tip of the shoulder blade and tip of the elbow. The midpoint was then lightly marked with a pen, and the arm was put in a relaxed position. The MUAC tape was then carefully positioned around the arm, making sure that it was not too tight or too loose. MUAC measurements of children were recorded in millimeters.

The presence of bilateral edema was determined among the toddlers by applying light pressure with both thumbs to both feet for three seconds. Edema is present if an imprint was left on either foot. If edema was detected, it was recorded in the questionnaire.

\section{Result and Discussion}

\subsection{Small talks and social recreation}

In order to gain people's trust and form good working relationships in the community, extension implementers occasionally communicate through small talks. This provides an opportunity to not just transmit new knowledge or recommendations, but it also devotes time to building up the confidence and interest of individuals in the community. The first few minutes of contact help establish a good rapport, particularly if it is the first meeting. Methods of establishing rapport and of initiating conversation differ from culture to culture. Small talk to break the ice is often an essential first step that gives both sides a chance to relax and get to know each other before more serious matters are discussed. Similarly, local customs should be followed as regards accepting hospitality. Recreational activities provide outlets for the community to relax, socialize, and engage with the newcomers.

Individuals in the community attended the events because it was fun, engaging, and made them "feel good," they said, especially the socializations where the extension workers and the community shared a feast. Since the extension implementers encouraged the students' involvement, it was an opportunity for the students to learn in community engagement and development as well. For the students, it created an avenue for the culturally relevant interventions to enrich their education and leadership skills. Thus, it pushed them to attend beyond student-led periods.

A recent study using an integrational approach to improve health awareness showed that community participants continued to attend beyond the formally announced activities, indicating the importance of developing enjoyable and sustainable 
interventions. This study also recommends that university faculty and students promote sustainability of their interventions by engaging communities to understand their preferences, and improve the long-range community health (Feinberg, Bowman, \& Lipman, 2016).

\subsection{Community involvement}

\subsubsection{Workshop and information, education, and communication materials dissemination}

Health education, behavior modification techniques, and storytelling were employed as approaches and strategies. The extension implementers of the college utilized locally available methods and media such as leaflets and posters. With the help of other Research, Development, and Extension (RDE) staff, the extension workers produced IEC materials aligned with the government health promotion programs. IEC materials used in storytelling are one of the strategies employed in some of the activities (Figure 2).
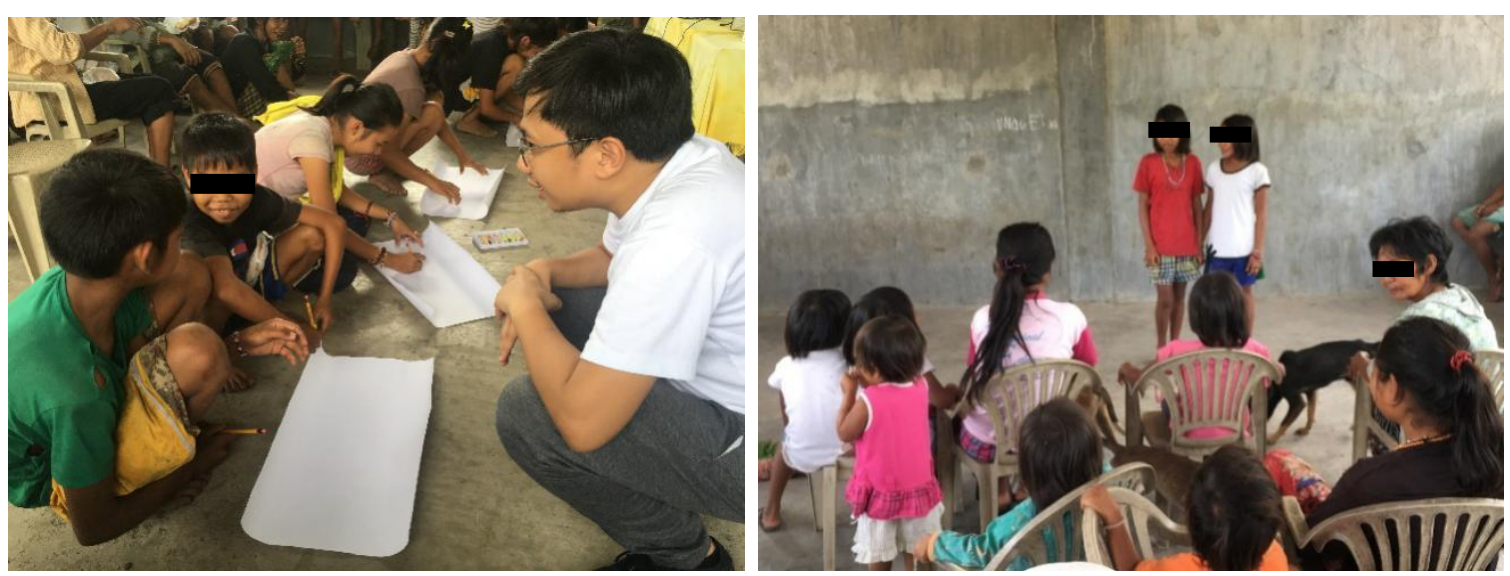

Fg. 2 Socialization with the community through drawing and talent showcasing Source: Author (2017)

The storytelling focused only on one health issue at a time. We look at health in a big picture - what is preventing people from being healthy? How this present scenario can be changed? And how does it affect community development?

Globally, IEC has been found to be effective in the implementation of health programs, as it encourages engagement and critical thinking among learners in communities. In the Philippines it is widely used in the implementation of different health services (Figure 3). In one study from India, IEC was found to be a neglected area in the national health 
program, with districts with inadequate budgets and human resources with poor implementation (Thakur, Jaswal, \& Grover, 2017).

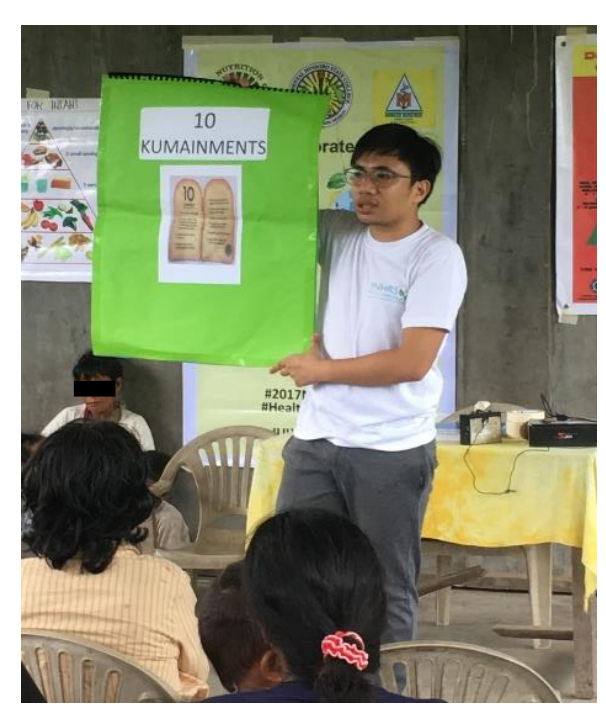

Fg. 3 health education implementation in the community Source: Author (2017)

Partnered with other health workers, extension workers assist in educating the community especially mothers, children, community health workers and leaders, in the targeted areas of health, nutrition, water, hygiene, and sanitation. The extension implementers conduct various health classes on the importance of health seeking, nutrition in the first 1000 days, nutrition in emergencies, preparation and storage of clean drinking water, preparation of oral hydrating solution, breastfeeding, expanded programs for immunization, deworming, hand washing, sanitation, and hygiene.

In various activities, behavior change techniques were employed, especially when focused on hygiene and sanitation. Clean water, safe removal of excretia, and personal hygiene are three key elements of any strategy to improve public health. In one of the activities, community participants were gathered around on ground with feces close-by a cup with food. The participants were encouraged to observe the following events: the flies landed on the feces....and a moment later, on the food. The facilitator picked up the food and tried to offer it to the participants. As expected, none of them accepted. The facilitator encouraged the participants to reflect and think of the consequences of open defecation. That sparked a conversation and learning engagement which encouraged the participant's conscious learning process, which they later were able to apply (Figure 4). 

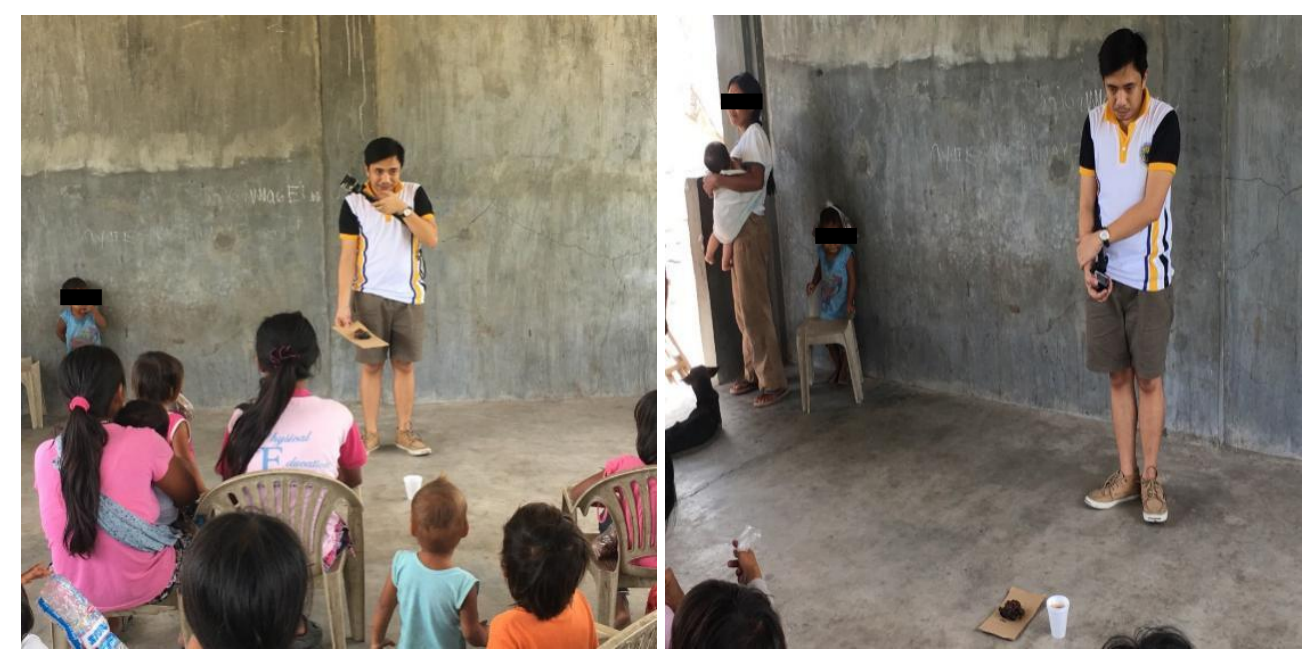

Fg. 4 Activities employed behavioral change and conscientization

Source: Author (2017)

Many times, the knowledge and attitudes of the community increase quickly. It is, however, critical to maintain and sustain the practices after the phase-out period. Defecation behaviors are greatly affected by the physical environment, particularly the the presence of clean and safe facility. Individually, defecation behavior were influenced by the motivation and habits especially when available, water was the preferred material for flushing, washing, anal cleansing and hand hygiene (Pfadenhauer \& Rehfuess, 2015).

In a study, it was revealed that WASH programs, more broadly, concentrates in creating initial behavioral changes, highlighting on the habituation of improved behaviors and behavioral maintenance. However, these approaches may bring regression back to unimproved behaviors and practices, and poor sustainability of behavioral outcomes and potential health impacts (Delea et al., 2019; Harter, Mosch, \& Mosler, 2018; Nery et al., 2019).

Table 1 shows the different activities that focus on the child's health and nutrition. In creating training designs and implementing activities, the following principles were considered:

1. In keeping with the Convention on the Rights of the Child, "every child has the right to access to care for the most prevalent causes of illness and death, as well as to measures to prevent them" (UN General Assembly, 1989).

2. Improving childcare and feeding will improve nutritional status of the children in the community. Since it is considered a cycle, a child's observed behavior on 
Artemio Morado Gonzales Jr | ASEAN Journal of Community Engagement | Volume 4, Number 1, 2020

proper food and hygiene practices will most likely practice this during adulthood or parenthood.

3. Households can prevent nutrition-related illness and water- and foodborne diseases by disposing of feces safely, by washing hands after defecation, before preparing meals, and before feeding children. Hence, integrating the water, sanitation, and hygiene (WASH) program is essential.

4. The First 1000 days has been called the "golden window of opportunity" for a comprehensive nutritional intervention to combat child stunting, underweight and wasting, at the same time contribute to complete child development.

Improved sanitation and washing of hands are one important action in reducing morbidity and mortality from diarrheal virus. However, creating a drastic change sanitation and hygiene is quite challenging. Households must make appropriate practice in an arena which is intensely private. Creating such choices requires that all institutional stakeholders collaborate effectively (Cairncross et al., 2010; Jakimow, 2008).

Nutritionally adequate and safe complementary feeding, starting from the age of six months up to 59 months, is one of the most effective interventions for reducing infant and child morbidity and malnutrition. Ensuring nourishment for Infant and Young Child Feeding (IYCF) is adhering to criteria such as food availability, access to food, utilization of food and stability/sustainability to achieve food security. Children who receive good nutrition in the first year of life grow healthier as they age. Good childhood nutrition has good outcomes, not only for their own health status but also for the national health and productivity (Salmon, 2015). 
Artemio Morado Gonzales Jr | ASEAN Journal of Community Engagement | Volume 4, Number 1, 2020

Table 1. Child Health and Nutrition Extension Activities Implemented

\begin{tabular}{|c|c|c|}
\hline Participants & Collaborating Agency & Topics Introduced \\
\hline Sitio dwellers & $\begin{array}{l}\text { Red Cross Youth Council, } \\
\text { Municipal Health Office (Rizal) }\end{array}$ & $\begin{array}{l}\text { Seminar-Workshop on } \\
\text { Nutrition in Emergencies }\end{array}$ \\
\hline Sitio dwellers & $\begin{array}{l}\text { Red Cross Youth Council, } \\
\text { Municipal Health Office (Rizal) }\end{array}$ & $\begin{array}{l}\text { Proper Hygiene in Focus } \\
\text { during Yuletide Season }\end{array}$ \\
\hline Sitio dwellers & $\begin{array}{l}\text { Red Cross Youth Council, } \\
\text { Municipal Health Office (Rizal) }\end{array}$ & $\begin{array}{l}\text { Seminar on Hygiene, } \\
\text { Sanitation and Health } \\
\text { Promotion }\end{array}$ \\
\hline Sitio dwellers & $\begin{array}{l}\text { Red Cross Youth Council, } \\
\text { Municipal Health Office (Rizal) }\end{array}$ & $\begin{array}{l}\text { Seminar on Nutrition in the } \\
\text { First } 1000 \text { Days of Baby's Life }\end{array}$ \\
\hline Sitio dwellers & $\begin{array}{l}\text { Red Cross Youth Council, } \\
\text { Municipal Health Office (Rizal) }\end{array}$ & $\begin{array}{l}\text { Seminar on Maternal and Child } \\
\text { Health with focus on Nutrition, } \\
\text { Hygiene and Sanitation }\end{array}$ \\
\hline $\begin{array}{l}\text { Rural health } \\
\text { midwives and } \\
\text { public health } \\
\text { nurses }\end{array}$ & $\begin{array}{l}\text { Municipal Health Offices in } \\
\text { SAMARICA District, Provincial } \\
\text { Governors Office (Occidental } \\
\text { Mindoro) }\end{array}$ & $\begin{array}{l}\text { Training-Workshop on } \\
\text { Conventional Integrated } \\
\text { Management of Childhood } \\
\text { Illness (IMCI) and IMCI- } \\
\text { Computerized Automated } \\
\text { Training Tools (I-CATT) for } \\
\text { Midwives }\end{array}$ \\
\hline $\begin{array}{l}\text { Barangay health } \\
\text { workers }\end{array}$ & $\begin{array}{l}\text { Local Government Unit of Rizal, } \\
\text { Occidental Mindoro }\end{array}$ & $\begin{array}{l}\text { Barangay Health Workers } \\
\text { Training }\end{array}$ \\
\hline Sitio dwellers & $\begin{array}{l}\text { Red Cross Youth Council, } \\
\text { Municipal Health Office (Rizal) }\end{array}$ & $\begin{array}{l}\text { Seminar on Infant and Child } \\
\text { Feeding and Nutrition }\end{array}$ \\
\hline Sitio d & $\begin{array}{l}\text { Barangay Manoot, LGU Rizal, } \\
\text { MHO Rizal }\end{array}$ & $\begin{array}{l}\text { Seminar on Child Health: } \\
\text { Water, Hygiene and Sanitation }\end{array}$ \\
\hline
\end{tabular}

\subsubsection{Training of Health Workers}

Community Health Workers (CHWs) bring their unique capacity to connect patients, communities, and health care systems to health care teams. In the Philippines, the firsthand workers for health are the BHW. In the virtue of Republic of the Philippines, Republic Act 7883 also known as The Barangay Health Workers' Benefits and Incentives Act of 1995, BHW refers to a "person who has undergone training programs under any accredited government and non-government organization and who voluntarily renders primary health care services in the community after having been accredited to function as such by the local health board in accordance with the guidelines promulgated by the Department of Health". In line with this, the extension implementers conducted seminars, trainings, and workshops to train the BHWs in standard operating procedures in doing routine health check-ups, and in simple measures for tending to the clients in the 
community. One of the training concentrations is the BHW role in the management of childhood illnesses and nutrition (Figure 5).

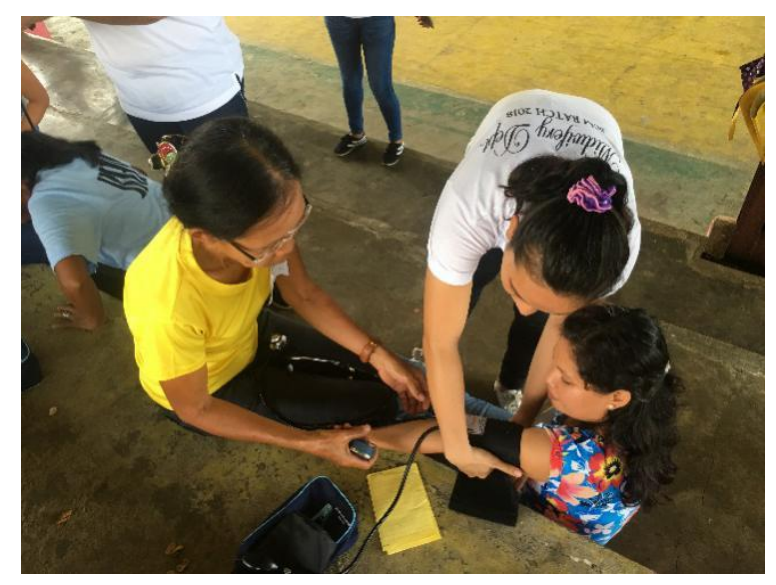

Fg. 5 Barangay Health Workers Training

Source: Author (2018)

Integrated Management of Childhood Illness (IMCI) Training was designed to equip health workers in the primary care setting with skills in the integrated management of sick infants and children. Rather than relying on laboratory support to diagnose an illness, workers are trained to use a few clinical signs and action-oriented classifications for diagnosis (Nguyen et al., 2013).

The success of the program greatly relies on the multi-sectoral and interdisciplinary approaches in community development which relates to the stakeholders within the health care team and the community organizations. This is due to the innovative structure for in creating of patient-centered approach in application of holistic care continuum across clients in different gender, age, health status, health concerns to promote inclusive and equitable health promotion (Gunderson et al., 2018). It was supported by a study remarking that training of CHWs removes barriers to service provision. Hence, CHWs may contribute substantially in addressing the child's health needs in the community (Tilahun et al., 2017).

\subsection{Impact assessment in preparation for phase out}

Impact of the program was measured by statistics and health indicators in the community. It has been shown that despite the efforts of the various blocks working in the health system, nutritional status in the community is still poor. High incidence of 
malnutrition (17\%), stunting (54.9\%) and underweight (37.7\%) was observed (Gonzales \& Salvador, 2020) as shown in the Table 2 below.

Proportion of complementary feeding started at six months was lower in a low-income community. Introduction of complementary feeding at six months of age is crucial for preventing malnutrition in infants (Chandwani, Prajapti, Rana, \& Sonaliya, 2015). By implementing the IYCF program, it was noted that continued education exposure and sustained impacts on IYCF knowledge and practices in intensive areas produced lasting benefits from interventions (Kim et al., 2018). This suggests scaling up by streamlining tools and strategies, increasing government focus, forming partnerships and communitybased health systems, and mainstreaming nationwide the unification and alignment of government and non-government agencies and organizations in all sectors (Sanghvi et al., 2016) to avoid duplication and redundancy.

Table 2. Prevalence of acute malnutrition, stunting and low body weight $(n=53)$

\begin{tabular}{lc}
\hline Indicator & Prevalence Rate \\
\hline Global malnutrition & $\mathbf{1 7 . 0}$ \\
Moderate malnutrition & 15.1 \\
Severe malnutrition & 1.9 \\
Stunting & $\mathbf{5 4 . 9}$ \\
Moderate stunting & 19.6 \\
Severe stunting & 35.3 \\
Underweight & $\mathbf{3 7 . 7}$ \\
Moderate underweight & 22.6 \\
Severe underweight & 15.1 \\
\hline
\end{tabular}

Source: Gonzales and Salvador (2020)

The Buhid Mangyans may experience similar difficulties in securing food at the household level. However, due to cultural variations, the level of food insecurity and coping mechanisms may vary across tribes (Declaro-Ruedas, 2015). It has been shown that nutrition is linked with food security in almost all communities. Agriculture and food production plays more active role in the economic and social aspects of development especially in health and nutrition. The main issue is building a food system that can lead to which could lead to improved food access, food security, nutrition and development (Fan \& Brzeska, 2016).

A study suggests that a systems approach can create policy interventions across different sectors, establishing programs that effectively improve access, affordability and 
Artemio Morado Gonzales Jr | ASEAN Journal of Community Engagement | Volume 4, Number 1, 2020

acceptable food sources and diet, contributing to better food and nutritional security for the population (Kawabata, Berardo, Mattei, \& de Pee, 2020). Another study suggests that, in order to respond to the rising challenge of the nutrition transition and to achieve zero hunger and malnutrition, policymakers and program managers must be equipped with better data to design adequate programs and policies that equitable access to nutrition (Ruel, Garrett, Yosef, \& Olivier, 2017).

Immunization was observed to be minimally practiced in the community despite the efforts of CHWs and other stakeholders, as shown in Table 3. Moreover, high incidence of diarrheal diseases and acute respiratory disease was observed in the community.

Table 3. Child health indicator in the community ( $\mathrm{n}=53)$

\begin{tabular}{lc}
\hline \multicolumn{1}{c}{ Indicators } & Percentage \\
\hline BCG vaccination (for 0-59 months) $^{*}$ & $37.7 \%$ \\
Measles vaccination (for 9-59 months)* & $48.1 \%$ \\
Vitamin A (for 6-59 months)* & $81.1 \%$ \\
Deworming (for 6-59 months)* & $81.1 \%$ \\
Place of consultation & $3.8 \%$ \\
$\quad$ Do not seek consultation & $11.3 \%$ \\
$\quad$ Hospital & $84.9 \%$ \\
Health center & $22.6 \%$ \\
Prevalence of diarrhea & $50.9 \%$ \\
\hline \multicolumn{2}{c}{ Prevalence of acute respiratory disease } \\
\hline
\end{tabular}

Lack of knowledge and awareness in cultural differences and cultural competency among health program implementers may lead to misunderstanding towards their health needs and may affect their access to the minimum available health services. To realize the benefit of health seeking and acceptance, appropriate health service should be offered to them (Mpimbaza et al., 2018). Low levels of education and cultural barriers may likewise make health information inaccessible due to low acceptance (Gadsden, Ford, \& Breiner, 2016). Similar study in the Philippines revealed that mothers failed to avail health services due to encountered barriers due to traditional beliefs (Titus, 2018). Thus, in implementing health services plans should be adoptive with the cultural pattern of the targeted population within a given community (Okoye et al., 2018) in order to create culture sensitive appropriate intervention. A study suggests applying more sensitive health programs and activities might improve efforts toward health care access and reduction of the burden of diseases (Thummapol, Barton, \& Park, 2018). 
The problems encountered by the extension workers were: the distance from the program implementers' station to remote areas was far and communication was sometimes difficult, especially with the dole-out attitude of the community, low and wrong health information system often observed mistaken health indicators, the language barriers intimidated people who were scared and hesitant to speak Tagalog or the Buhid language. Thus, the programs could enhance their health knowledge and practices by using other forms of extension modalities. Hailu (2018) stated that attribution of all improvements in the health sector to the effective implementation of health extension is difficult to acknowledge at this point and there is only a loose coordination among different government bodies taking concerted measures. Therefore, health system consideration must include deployment of health professionals as health extension workers with proper and acceptable compensation for motivation.

\section{Conclusion}

Health education, small group techniques, demonstrations, storytelling, informal talks and open forums were the methods and techniques employed to implement the program. The common tools used were seating arrangements, flipcharting, props, social hours, and recreation. In terms of the evaluation of the program, child health remains lackluster despite the efforts of different blocks working in the health system. Thus, this program could enhance their health knowledge and practice in other forms of extension modalities.

The study recommends student involvement for extension mobilization, particularly to the department that has only a few faculty members. This strategy would really suggest that extension activities effectively facilitate the programs/projects. The impact study of the extension program must be conducted to determine how much the program contributed to raising the quality of life among Buhids. A mechanism of the extension program must be instituted to monitor, evaluate, and sustain linkage-extension projects. The trainers would recommend learning the indigenous languages and dialects to obtain the correct and accurate information and provide quality health delivery services. Good interpersonal communication and counseling skills may initiate the harmonious working relationship and establish rapport, so that health programs can offer them appropriately. More linkages mean more chances to effectively advocate for extension program funding, 
Artemio Morado Gonzales Jr | ASEAN Journal of Community Engagement | Volume 4, Number 1, 2020

logistics, and sometimes human resources. It has been established that the good working relationship between these partners in enabling the sustained effectiveness of the program to meet the SDGs targets by 2030 . Capability building can be considered to find other efficient and effective extension modalities waiting for acceptance of their applications.

\section{Author Contribution}

Artemio Morado Gonzales Jr conceived of the presented idea, developed the theory, performed data gathering procedures, verified the analytical methods, and ensured integrity of the result.

\section{Acknowledgements}

This study was supported by the Research, Development and Extension Unit of Occidental Mindoro State College. The conduct of the different extension activities prospered with the approval of the RDE Directors of the College (Ms. Susanita G. Lumbo and Ms. Mary Yole Apple Declaro-Ruedas). Also, the author acknowledges the faculty of the Midwifery Department; College of Arts, Sciences, and Technology for the technical support as resource persons in the implementation of the extension activities. Moreover, the author wants to acknowledge, Mr. Ryan Mark A. Ambong (Science Research Specialist) and Mr. Leoniel S. Bais (Science Research Analyst) for the verification and certification of the data presented. This is also to acknowledge the local government unit and municipal health office of Rizal, Occidental Mindoro for the support of different activities in the locale. Lastly, this is to acknowledge the community/tribal leaders and the people of Sitio Bato Singit in the acceptance and accommodation of different extension activities of the college.

\section{References}

Aboud, F. E., \& Yousafzai, A. K. (2018). Health and nutrition interventions for infant development. In The Lancet Child and Adolescent Health, 2(4), 231-233 
Agbezuge, S. (2018). Environmental Sanitation: A Human Right to Ghanaians. Journal of Law, Policy and Globalization, 72(2018), 30-37.

\section{https://www.iiste.org/Journals/index.php/JLPG/article/view/42031/43274}

Aggarwal, P., \& Kakkar, R. (2019). National Nutrition Strategy: The Needed Timely Modification to Make Integrated Child Development Scheme More Effective. In Indian Journal of Pediatrics, 86, 628-632.

https://doi.org/10.1007/s12098-019-02869-9

Belizario, V. Y., Liwanag, H. J. C., Naig, J. R. A., Chua, P. L. C., Madamba, M. I., \& Dahildahil, R. O. (2015). Parasitological and nutritional status of school-age and preschool-age children in four villages in Southern Leyte, Philippines: Lessons for monitoring the outcome of Community-Led Total Sanitation. Acta Tropica, 141(Part A), 16-24

https://doi.org/10.1016/j.actatropica.2014.09.008

Cairncross, S., Hunt, C., Boisson, S., Bostoen, K., Curtis, V., Fung, I. C., \& Schmidt, W.-P. (2010). Water, sanitation and hygiene for the prevention of diarrhoea. International Journal of Epidemiology, 39(1), i193-i205.

https://doi.org/https://doi.org/10.1093/ije/dyq035

Cetrángolo, O., Mesa-Lago, C., Lazaro, G., \& Carisma, S. K. (2013). Health Care in the Philippines: Challenges and Ways Forward. In Friedrich-Ebert-Stiftung-Philippine Office.

\section{http://www.worldcat.org/oclc/906059402}

Chandwani, H., Prajapati, A., Rana, B., \& Sonaliya, K. (2015). Assessment of infant and young child feeding practices with special emphasis on IYCF indicators in a field practice area of Rural Health Training Centre at Dabhoda, Gujarat, India. International Journal of Medical Science and Public Health, 4(10), 1414-1419. 
Artemio Morado Gonzales Jr | ASEAN Journal of Community Engagement | Volume 4, Number 1, 2020

Clark, H., Coll-Seck, A. M., Banerjee, A., Peterson, S., Dalglish, S. L., Ameratunga, S., ... Balabanova, D., Bhan, M. K., Bhutta, Z. A., Borrazzo, J., Claeson, M., Doherty, T., El-Jardali, F., George, A. S., Gichaga, A., Gram, L., Hipgrave, D. B., Kwamie, A., Meng, Q., ... Costello, A. (2020). A future for the world's children? A WHO-UNICEF-Lancet Commission. Lancet (London, England), 395(10224), 605-658.

https://doi.org/10.1016/S0140-6736(19)32540-1

Co, E. E. A., Caragay, R. N., Lopez, J. C. F., Sia, I. C., Estacio, L. R., Lam, H. Y., ... Madamba, J. S., Abola, R. I. B., \& Villena, M. F. A. (2018). Scaling up primary health care in the philippines: Lessons from a systematic review of experiences of community-based health programs. Acta Medica Philippina, 52(8), 194-202.

https://hrdo.upm.edu.ph/index.php/acta/article/view/448/406

Dawson, R., \& Avoseh, M. B. (2018). Freire's Conscientization and the Global Student: Towards Emancipatory Transformation. Commission for International Adult Education. http://files.eric.ed.gov/fulltext/ED597497.pdf

De Buck, E., Hannes, K., Cargo, M., Van Remoortel, H., Vande veegaete, A., Mosler, H. J., ... Govender, T., Vandekerckhove, P., \& Young, T. (2018). Engagement of stakeholders in the development of a Theory of Change for handwashing and sanitation behaviour change. International Journal of Environmental Health Research, 28(1), 8-22.

https://doi.org/10.1080/09603123.2017.1415306

Declaro-Ruedas, M. Y. A. (2015). Rationing Change as Coping Strategy Employed by Buhid Households against Food Insecurity. JPAIR Multidisciplinary Research, 19(1)

https://doi.org/10.7719/jpair.v19i1.312

Declaro-Ruedas, M. Y. A., \& Lumbo, S. G. (2017). Extension at crossroads: management strategies employed in the Green Wealth Extension Program of the Occidental Mindoro State College.

Delea, M. G., Snyder, J. S., Belew, M., Caruso, B. A., Garn, J. V., Sclar, G. D., ... Woreta, M., Zewudie, K., Gebremariam, A., \& Freeman, M. C. (2019). Design of a parallel clusterrandomized trial assessing the impact of a demand-side sanitation and hygiene intervention on sustained behavior change and mental well-being in rural and periurban Amhara, Ethiopia: Andilaye study protocol. BMC Public Health, 19(801). 
Desta, S. H., \& Basha, S. Y. (2017). The Role of Health Extension Workers in Primary Health Care in AsgedeTsi'mbla District: A Case of Lim'at T'abya Health Post. International Journal of Social Sciences and Management, 4(4), 248-266.

https://doi.org/10.3126/ijssm.v4i4.18504

Fadare, O., Amare, M., Mavrotas, G., Akerele, D., \& Ogunniyi, A. (2019). Mother's nutritionrelated knowledge and child nutrition outcomes: Empirical evidence from Nigeria. PLOS ONE, 14(4), e0215110.

https://doi.org/10.1371/journal.pone.0212775

Fan, S., \& Brzeska, J. (2016). Sustainable food security and nutrition: Demystifying conventional beliefs. Global Food Security, 11, 11-16.

\section{https://doi.org/10.1016/j.gfs.2016.03.005}

Feinberg, J. L., Bowman, C., \& Lipman, T. H. (2016). Dance for health: The importance of community engagement and project sustainability. Journal of Nursing Education and Practice, 7(1), 89-94.

\section{https://doi.org/10.5430/jnep.v7n1p89}

Ferguson, A., Swan, L. E. T., \& Im, H. (2019). A Domains Approach to Perceived Problems and Solutions for Community Empowerment in an Urban Refugee Community in Kenya. Global Social Welfare.

\section{https://doi.org/10.1007/s40609-019-00150-7}

Ferreira, F. D. S. (2017). Critical sustainability studies: A holistic and visionary conception of socio-ecological conscientization. Journal of Sustainable Education, 7, 263-274.

\section{https://doi.org/10.1145/1364782.1364786}

Freire, P. (1998). Education for Critical Consciousness. In The Paulo Freire Reader.

Gadsden, V. L., Ford, M., \& Breiner, H. (2016). Parenting matters: Supporting parents of children ages 0-8. In Parenting Matters: Supporting Parents of Children Ages 0-8. https://doi.org/10.17226/21868

Gonzales, A. J. M., \& Salvador, M. N. (2020). Nutritional Status and Infant and Young Child Feeding (IYCF) Practices among Buhid Mangyan Tribe, Occidental Mindoro Philippines. International Journal of Child Health and Nutrition, 9(2), 47-54. 
Artemio Morado Gonzales Jr | ASEAN Journal of Community Engagement | Volume 4, Number 1, 2020

Grantham-Mcgregor, S. M., Fernald, L. C. H., Kagawa, R. M. C., \& Walker, S. (2014). Effects of integrated child development and nutrition interventions on child development and nutritional status. Annals of the New York Academy of Sciences, 1308(1), 11-32.

https://doi.org/10.1111/nyas.12284

Gunderson, J. M., Wieland, M. L., Quirindongo-Cedeno, O., Asiedu, G. B., Ridgeway, J. L., O’Brien, M. W., ... \& Njeru, J. W. (2018). Community health workers as an extension of care coordination in primary care a community-based cosupervisory model. Journal of Ambulatory Care Management, 41(4), 333-340.

https://doi.org/10.1097/JAC.0000000000000255

Hailu, D. M. (2018). Ethiopias health extension program: Opportunities and challenges of its implementation in Shiromeda. International Journal of Sociology and Anthropology, $10(5), 53-58$.

https://doi.org/10.5897/IJSA2017.0723

Harter, M., Mosch, S., \& Mosler, H. J. (2018). How does Community-Led Total Sanitation (CLTS) affect latrine ownership? A quantitative case study from Mozambique. BMC Public Health, 18(387). https://doi.org/10.1186/s12889-018-5287-y

Hoffmann, R. (2017). When Communities Participate in Primary Health Care: A Randomized Controlled Trial of a Community Health Worker Program in the Philippines. 2017 International Population Conference. IUSSP.

http://www.mzes.uni-mannheim.de/d7/de/events/when-communities-participatein-primary-health-care-a-randomized-controlled-trial-of-a-community-healthworker-program

Horrill, T., McMillan, D. E., Schultz, A. S. H., \& Thompson, G. (2018). Understanding access to healthcare among Indigenous peoples: A comparative analysis of biomedical and postcolonial perspectives. Nursing Inquiry, 25, e12237.

https://doi.org/10.1111/nin.12237 
Jakimow, T. (2008). Answering the critics: The potential and limitations of the knowledge agenda as a practical response to post-development critiques. Progress in Development Studies, 8(4), 311-323.

https://doi.org/10.1177/146499340800800401

Kawabata, M., Berardo, A., Mattei, P., \& de Pee, S. (2020). Food security and nutrition challenges in Tajikistan: Opportunities for a systems approach. Food Policy, 101872. https://doi.org/10.1016/j.foodpol.2020.101872

Kim, S. S., Nguyen, P. H., Tran, L. M., Sanghvi, T., Mahmud, Z., Haque, M. R., ... Afsana, K., Frongillo, E. A., Ruel, M. T., \& Menon, P. (2018). Large-Scale Social and Behavior Change Communication Interventions Have Sustained Impacts on Infant and Young Child Feeding Knowledge and Practices: Results of a 2-Year Follow-Up Study in Bangladesh. Journal of Nutrition, 148(10), 1605-1614.

\section{https://doi.org/10.1093/jn/nxy147}

Masters, W. A., Rosettie, K., Kranz, S., Pedersen, S. H., Webb, P., Danaei, G., ... Mozaffarian, D., Adekugbe, O., Adhikar, R. K., Amatya, A., Atomsa, G. E., Badham, J., Bhattacharjee, L., Bhattarai, M., Baye, K., Beyero, M., Brahmbhatt, V., Chandrasekhar, S., Chandyo, R. K., ... Wendelin, A. (2018). Priority interventions to improve maternal and child diets in SubSaharan Africa and South Asia. Maternal and Child Nutrition, 14(2), e12526.

https://doi.org/10.1111/mcn.12526

Mbuya, M. N. N., Jones, A. D., Ntozini, R., Humphrey, J. H., Moulton, L. H., Stoltzfus, R. J., \& Maluccio, J. A. (2015). Theory-driven process evaluation of the SHINE trial using a program impact pathway approach. Clinical Infectious Diseases, 61(7), 752-758.

https://doi.org/10.1093/cid/civ716

Mpimbaza, A., Katahoire, A., Rosenthal, P. J., Karamagi, C., \& Ndeezi, G. (2018). Caregiver responses and association with delayed care-seeking in children with uncomplicated and severe malaria. Malaria Journal, 17(476). 
Artemio Morado Gonzales Jr | ASEAN Journal of Community Engagement | Volume 4, Number 1, 2020

Nery, S. V., Traub, R. J., McCarthy, J. S., Clarke, N. E., Amaral, S., Llewellyn, S., ... Weking, E., Richardson, A., Campbell, S. J., Gray, D. J., Vallely, A. J., Williams, G. M., Andrews, R. M., \& Clements, A. C. A. (2019). Wash for worms: A cluster-randomized controlled trial of the impact of a community integrated water, sanitation, and hygiene and deworming intervention on soil-transmitted helminth infections. American Journal of Tropical Medicine and Hygiene, 100(3), 750-761.

https://doi.org/10.4269/ajtmh.18-0705

NewCAPP. (2014). The ties that bind: The Buhid Mangyan People of Mindoro, their Sacred Lands and Medicine Mountain. newcapp.files.wordpress.com/2014/02/buhidmangyan1.pdf

Nguyen, D. T. K., Leung, K. K., McIntyre, L., Ghali, W. A., \& Sauve, R. (2013). Does Integrated Management of Childhood Illness (IMCI) Training Improve the Skills of Health Workers? A Systematic Review and Meta-Analysis. PLoS ONE, 8(6), e66030. https://doi.org/10.1371/journal.pone.0066030

Okoye, R. S., Bell, L., \& Papadopoulos. (2018). Relevance of culturally-appropriate approaches in health promotion : a look at Igbo philosophies in dealing with eye care challenges in Nigeria . Journal of the Nigerian Optometric Associatiom, 20(2), 37-45. https://www.ajol.info/index.php/jnoa/article/view/173701

Parvez, S. M., Azad, R., Rahman, M., Unicomb, L., Ram, P. K., Naser, A. M., ... Stewart, C. P., Jannat, K., Rahman, M. J., Leontsini, E., Winch, P. J., \& Luby, S. P. (2018). Achieving optimal technology and behavioral uptake of single and combined interventions of water, sanitation hygiene and nutrition, in an efficacy trial (WASH benefits) in rural Bangladesh. Trials, 19(358).

\section{https://doi.org/10.1186/s13063-018-2710-8}

Pfadenhauer, L. M., \& Rehfuess, E. (2015). Towards Effective and Socio-Culturally Appropriate Sanitation and Hygiene Interventions in the Philippines: A Mixed Method Approach. International Journal of Environmental Research and Public Health, 12(2), 1902-1927. 
Prüss-Ustün, A., Wolf, J., Corvalán, C., Neville, T., Bos, R., \& Neira, M. (2017). Diseases due to unhealthy environments: An updated estimate of the global burden of disease attributable to environmental determinants of health. Journal of Public Health, 39(3), 464-475.

\section{https://doi.org/10.1093/pubmed/fdw085}

Ribeiro, A. I., Krainski, E. T., Autran, R., Teixeira, H., Carvalho, M. S., \& de Pina, M. de F. (2016). The influence of socioeconomic, biogeophysical and built environment on oldage survival in a Southern European city. Health and Place, 41, 100-109.

\section{https://doi.org/10.1016/j.healthplace.2016.08.008}

Ruel M.T., Garrett J., Yosef S., Olivier M. (2017) Urbanization, Food Security and Nutrition. In: de Pee S., Taren D., Bloem M. (eds) Nutrition and Health in a Developing World. Nutrition and Health. Humana Press, Cham.

https://doi.org/10.1007/978-3-319-43739-2_32

Russell, F., \& Azzopardi, P. (2019). WASH: a basic human right and essential intervention for child health and development. The Lancet Global Health, 7(4), e417. https://doi.org/10.1016/S2214-109X(19)30078-6

Salmon, L. (2015). Food security for infants and young children: An opportunity for breastfeeding policy? International Breastfeeding Journal, 10(7). https://doi.org/10.1186/s13006-015-0029-6

Sanghvi, T., Haque, R., Roy, S., Afsana, K., Seidel, R., Islam, S., ... Jimerson, A., \& Baker, J. (2016). Achieving behaviour change at scale: Alive \& Thrive's infant and young child feeding programme in Bangladesh. Maternal and Child Nutrition, 12(S1), 141-154. https://doi.org/10.1111/mcn.12277

Sesan, T., Jewitt, S., Clifford, M., \& Ray, C. (2018). Toilet training: what can the cookstove sector learn from improved sanitation promotion? International Journal of Environmental Health Research, 28(6), 667-682. https://doi.org/10.1080/09603123.2018.1503235

Shrivastava, S., Shrivastava, P., \& Ramasamy, J. (2016). Preventing diseases through promotion of a healthier environment: World Health Organization. In Annals of Tropical Medicine and Public Health, 9(5), 364-365. 
Artemio Morado Gonzales Jr | ASEAN Journal of Community Engagement | Volume 4, Number 1, 2020

Srigley, J. A., Corace, K., Hargadon, D. P., Yu, D., MacDonald, T., Fabrigar, L., \& Garber, G. (2015). Applying psychological frameworks of behaviour change to improve healthcare worker hand hygiene: A systematic review. Journal of Hospital Infection, 91(3), 202-210.

\section{https://doi.org/10.1016/j.jhin.2015.06.019}

Stańczyk, P., \& Gdański, U. (2017). Didactics and politics in Paulo Freire 's philosophy of education: On the abandonment of the concept of conscientization. 0-1.

http://repozytorium.ukw.edu.pl/handle/item/6474

Steinmetz, H., Knappstein, M., Ajzen, I., Schmidt, P., \& Kabst, R. (2016). How effective are behavior change interventions based on the theory of planned behavior?: A three-level meta analysis. Zeitschrift fur Psychologie / Journal of Psychology, 224(3), 216-233.

https://doi.org/10.1027/2151-2604/a000255

Tangcharoensathien, V., Witthayapipopsakul, W., Panichkriangkrai, W., Patcharanarumol, W., \& Mills, A. (2018). Health systems development in Thailand: a solid platform for successful implementation of universal health coverage. The Lancet, 391(10126), 1205-1233.

\section{https://doi.org/10.1016/S0140-6736(18)30198-3}

Thakur, J., Jaswal, N., \& Grover, A. (2017). Is focus on prevention missing in national health programs? A situation analysis of IEC/BCC/Health promotion activities in a district setting of Punjab and Haryana. Indian Journal of Community Medicine, 42(1), 30-36. https://doi.org/10.4103/0970-0218.199795

Thummapol, O., Barton, S., \& Park, T. (2018). Healthcare Access Experiences Among Indigenous Women in Northern Rural Thailand: A Focused Ethnographic Study. Central Asian Journal of Global Health, 42(1), 30-36.

https://doi.org/10.5195/cajgh.2018.328

Tilahun, D., Hanlon, C., Araya, M., Davey, B., Hoekstra, R. A., \& Fekadu, A. (2017). Training needs and perspectives of community health workers in relation to integrating child mental health care into primary health care in a rural setting in sub-Saharan Africa: A mixed methods study. International Journal of Mental Health Systems, 11(15). 
Titus, A. T. (2018). Maternal Access to Health Services by Pregnant Mothers in Bacnotan, La Union, Philippines. Health Notions, 2(2), 151-158.

http://heanoti.com/index.php/hn/article/view/hn20201

Tucker, C. M., Roncoroni, J., Wippold, G. M., Marsiske, M., Flenar, D. J., \& Hultgren, K. (2018). Health Self-Empowerment Theory: Predicting Health Behaviors and BMI in Culturally Diverse Adults. Family and Community Health, 41(3), 168-177.

https://doi.org/10.1097/FCH.0000000000000195

UN General Assembly. (1989). Convention on the rights of a child. United Nations, Treaty Series.

https://digitalcommons.ilr.cornell.edu/cgi/viewcontent.cgi?article=1007\&context=c hild

United Nations. (2007). UNDRIP United Nations General Assembly Declaration of the Rights of Indigenous Peoples. In a/Res/61/295. https://www.un.org/esa/socdev/unpfii/documents/DRIPS_en.pdf

Vasan, A., Mabey, D. C., Chaudhri, S., Epstein, H. A. B., \& Lawn, S. D. (2017). Support and performance improvement for primary health care workers in low- and middleincome countries: A scoping review of intervention design and methods. In Health Policy and Planning, 32(3), 437-452.

https://doi.org/10.1093/heapol/czw144

Yuesti, K. S. A., \& Sumantra K. (2017). Empowerment on the Knowledge and Learning Organization for Community Development. Scientific Research Journal (SCIRJ), V(IX), 96-101.

http://www.scirj.org/papers-0917/scirj-P0917439.pdf

Zhou, X., Li, Z., Zheng, T., Yan, Y., Li, P., Odey, E. A., ... Mang, H. P., \& Uddin, S. M. N. (2018). Review of global sanitation development. Environment International, 120, 246-261. 